\title{
Histological, hormonal and transcriptomic reveal the changes upon gibberellin- induced parthenocarpy in pear fruit
}

Lulu Liu', Zhigang Wang ${ }^{1}$, Jianlong Liu', Fengxia Liu', Rui Zhai ${ }^{1}$, Chunqin Zhu', Huibin Wang ${ }^{1}$, Fengwang Ma ${ }^{1}$ and Lingfei $\mathrm{Xu}^{1}$

\begin{abstract}
Phytohormones play crucial roles in fruit set regulation and development. Here, gibberellins $\left(G A_{4+7}\right)$, but not $G A_{3}$, induced pear parthenocarpy. To systematically investigate the changes upon $\mathrm{GA}_{4+7}$ induced pear parthenocarpy, dynamic changes in histology, hormone and transcript levels were observed and identified in unpollinated, pollinated and $\mathrm{GA}_{4+7}$-treated ovaries. Mesocarp cells continued developing in both $\mathrm{GA}_{4+7}$-treated and pollinated ovaries. In unpollinated ovaries, mesocarp cells stopped developing 14 days after anthesis. During fruit set process, $\mathrm{GA}_{4+7}$, but not $\mathrm{GA}_{1+3}$, increased after pollination. Abscisic acid (ABA) accumulation was significantly repressed by $\mathrm{GA}_{4+7}$ or pollination, but under unpollinated conditions, ABA was produced in large quantities. Moreover, indole-3-acetic acid biosynthesis was not induced by $\mathrm{GA}_{4+7}$ or pollination treatments. Details of this GA-auxin-ABA cross-linked gene network were determined by a comparative transcriptome analysis. The indole-3-acetic acid transport-related genes, mainly auxin efflux carrier component genes, were induced in both $\mathrm{GA}_{4+7}$-treated and pollinated ovaries. ABA biosynthetic genes of the 9-cis-epoxycarotenoid dioxygenase family were repressed by $\mathrm{GA}_{4+7}$ and pollination. Moreover, directly related genes in the downstream parthenocarpy network involved in cell division and expansion (upregulated), and MADSbox family genes (downregulated), were also identified. Thus, a model of GA-induced hormonal balance and its effects on parthenocarpy were established.
\end{abstract}

\section{Introduction}

For most plants, fruit set and development are triggered by pollination and fertilisation, which are highly sensitive to environmental conditions ${ }^{1}$, and unsuitable temperatures, rain and high wind speeds negatively affect pollination ${ }^{2}$. Most fruit species, including pear, apple and cherry, exhibit natural self-incompatibility, and at least two inter-compatible cultivars are necessary to guarantee successful pollination in an orchard, which wastes land and resources. Parthenocarpic fruit set is independent of pollination and, therefore, does not require pollinizers. Previous studies showed that phytohormones, such as

\footnotetext{
Correspondence: Lingfei Xu (lingfxu2013@sina.com)

'Institution: College of Horticulture, Northwest A\&F University, Taicheng Road NO.3, Yangling, Shaanxi Province, China

Lulu Liu, Zhigang Wang and Jianlong Liu contribution equally to this work.
}

auxins and gibberellins (GAs), can promote parthenocarpy in several species ${ }^{3-7}$. Mesejo et al. ${ }^{8}$ showed that GA promotes cell division in ovary walls, causing fruit set. In addition to these hormones, other phytohormones, such as cytokinins, ethylene and abscisic acid (ABA), also take part in fruit set ${ }^{9}$. However, the precise roles of these hormones in regulating parthenocarpic fruit set and development are still poorly understood.

At present, the molecular mechanisms of parthenocarpic fruit set are still unclear in woody fruit trees, with only a few components related to this process having been uncovered. Two auxin response factors (ARFs), namely $A R F 7$ and $A R F 8$ had been shown associate with parthenocarpy. Transgenic tomato with decreased SIARF7 levels formed parthenocarpic fruit ${ }^{10}$, and a natural parthenocarpic eggplant mutant showed that $A R F 8$ 
is downregulated in buds compared with in wild-type plants $^{11}$. Thus, both $A R F 7$ and $A R F 8$ transcription factors are important negative regulators during fruit set. Auxin/indole-3-acetic acid (Aux/IAA) proteins are transcriptional regulators involved in auxin regulated plant development, and a loss-of-function IAA9 mutant tomato formed parthenocarpic fruit ${ }^{12}$, suggesting that $I A A 9$ is also a negative regulator of auxin involved in regulating parthenocarpic fruit set. GA signalling in particular plays an important role in regulating parthenocarpic fruit set because the increased auxin content in ovaries produced by parthenocarpic tomato is mediated through $\mathrm{GA}^{13}$. Moreover, tomato mutants pat and pat-2 increase the expression levels of GA biosynthetic genes, increasing the GA content, which forms parthenocarpic fruit ${ }^{14}$. The GA 20-oxidase (GA20ox) family of genes catalyse inactive $\mathrm{GA}$ to active $\mathrm{GA}$, and overexpressing the citrus gene CcGA20ox1 in tomato led to the development of parthenocarpic fruits ${ }^{15}$. In addition, GA2oxs are a type of catabolic enzyme that deactivate active GA. The silencing of all five GA2ox genes in transgenic tomato plants led to a significant increase in the $\mathrm{GA}_{4}$ content, and the plants exhibited the ability to develop parthenocarpically ${ }^{16}$. DELLA proteins are important negative regulators in the GA signalling pathway that restrict growth and development. Silencing of SIDELLA in tomato can induce parthenocarpic fruits ${ }^{17}$. GA depletes the DELLA protein ${ }^{18,19}$ and releases the repression of GA-response genes.

In addition, silencing of a tomato floral organspecification gene, TM29, a SEPELLATA-like MCM1, AGAMOUS, DEFICIENCE and SRF (MADS) box gene, also caused seedless fruits ${ }^{20}$. The loss-of-function mutation of MdPI, a MADS-box transcription factor, produces parthenocarpic fruit in apple ${ }^{21}$. Recently, the MADS box gene AGL6 was shown to regulate parthenocarpy in tomato, and loss function of SIAGAMOUS-LIKE 6 result in tomato facultative parthenocarpy ${ }^{22}$.

Most cultivated pears are self-incompatible; therefore, understanding the mechanisms of GA-induced parthenocarpic fruit would have great benefits for both production practices and theoretical studies. Here we studied changes upon gibberellins $\left(\mathrm{GA}_{4+7}\right)$-induced parthenocarpic pear fruit set at the histological, hormonal and transcriptome levels, which have been little studied previously. The aims of the study were: (1) to evaluate the effects of exogenous gibberellic acid $\left(\mathrm{GA}_{3}\right)$ and $\mathrm{GA}_{4+7}$ on parthenocarpic fruit set in 'Dangshansuli' (Pyrus bretschneideri Rehd.) to determine whether $\mathrm{GA}_{4+7}$, or $\mathrm{GA}_{3}$, could induce parthenocarpy in pear; (2) to observe the ovaries of unpollinated, pollinated and a $75 \mathrm{mg} \mathrm{L}^{-1} \mathrm{GA}_{4+7}$ treatment of 'Dangshansuli' during early stages using morphological and histological methods to explore the similarities and differences among these treatments; (3) to measure gibberellins, auxin and abscisic acid levels to study the hormone balance effects in fruit set; and (4) to perform an RNA sequencing (RNA-Seq) analysis of the ovary transcriptomes at three stages, 3, 9 and 14 days after anthesis (DAA), to study the molecular regulatory mechanism of $\mathrm{GA}_{4+7}$-induced parthenocarpy in pear.

\section{Materials and methods}

\section{Plant materials and experimental treatments}

Experiments were carried out in a pear orchard located in Meixian, Shaanxi Province, China $\left(34.29^{\circ} \mathrm{N}, 107.76^{\circ} \mathrm{E}\right.$, and $514 \mathrm{~m}$ above sea level). The average annual precipitation is $574.6 \mathrm{~mm}$, and the average annual temperature is $12.7^{\circ} \mathrm{C}$.

Eight treatments, the unpollinated (control), 25, 50 and $75 \mathrm{mg} \mathrm{L}^{-1} \mathrm{GA}_{3}, 25,50$ and $75 \mathrm{mg} \mathrm{L}^{-1} \mathrm{GA}_{4+7}$, and hand pollinated, were applied to 15-year-old 'Dangshansuli' trees, which were grafted onto $P$. betulifolia Bge rootstocks. Three branches of each treatment were used as three replicates. Two days before anthesis, all of the treatments and the control were bagged to prohibit pollination. Water was sprayed on unpollinated flowers as the unpollinated treatment. Solutions of $\mathrm{GA}_{3}$ alone at 25 , 50 and $75 \mathrm{mg} \mathrm{L}^{-1}$, and $\mathrm{GA}_{4+7}$ alone at 25,50 and $75 \mathrm{mg}$ $\mathrm{L}^{-1}$, were sprayed on unpollinated flowers of "Dangshansuli" at anthesis. Hand pollination was carried out at the same time. Then, 30 fruits per treatment were randomly sampled for the determination of hormone levels, morphological and cytological observations, and RNA sequencing at each sampling time point. Flowers/fruits were collected at $0,3,9,14$ and 153 DAA.

A part of each sample was immediately fixed in formaldehyde-acetic acid-alcohol for histological observation, while the rest of the samples were frozen in liquid nitrogen and then stored at $-80^{\circ} \mathrm{C}$ for further assays.

\section{Determination of fruit set rate}

A total of 30 blooms on each branch were labelled and bagged immediately after treatments. At 20 DAA, the bags were removed. The formula used to calculate the fruit set rate was as follows:

$$
\begin{array}{r}
\text { Fruit set rate }(\%) \\
=(\text { Number of fruitlets remaining } / 30) \times 100 .
\end{array}
$$

\section{Phytohormone analysis}

Samples of $0.2 \mathrm{~g}$ were ground in an ice-cold mortar with $8 \mathrm{~mL}$ of $80 \%$ (v/v) methanol extraction medium that contained $1 \mathrm{mM}$ butylated hydroxytoluene as an antioxidant 22. The extracts were incubated at $4{ }^{\circ} \mathrm{C}$ for $4 \mathrm{~h}$ and then centrifuged at 3500 r.p.m. for $8 \mathrm{~min}$ at $4{ }^{\circ} \mathrm{C}$. The supernatants were passed through Chromosep C18 columns (C18 Sep-Pak Cartridge; Waters Corporation, Millford, MA, USA), which were washed with $10 \mathrm{~mL}$ of 
$100 \%$ and $5 \mathrm{~mL}$ of $80 \%(\mathrm{v} / \mathrm{v})$ methanol. The hormone sediments were dried under nitrogen gas and then dissolved in $2 \mathrm{~mL}$ of phosphate-buffered saline (PBS) containing $0.1 \%(\mathrm{v} / \mathrm{v})$ Tween 20 and $0.1 \%(\mathrm{w} / \mathrm{v})$ gelatine ( $\mathrm{pH} 7.5)$.

Phytohormones were separately analysed using $\mathrm{GA}_{1+3}$, $\mathrm{GA}_{4+7}$, IAA and ABA ELISA Kits produced by the Phytohormones Research Institute, China Agricultural University, China. Yang's method for quantitative phytohormone determination was used ${ }^{23}$.

\section{Paraffin sectioning}

To conduct the histological observation, fruit samples of unpollinated, pollinated and $\mathrm{GA}_{4+7}$ treatments were collected at 3, 9 and 14 DAA, immediately fixed in formaldehyde-acetic acid-alcohol fixative ${ }^{24}$ and stored at $4{ }^{\circ} \mathrm{C}$. The ovaries were dehydrated in an ethanol/xylene series and embedded in paraffin, $10 \mathrm{~s}$ into $8-\mu \mathrm{m}$-thick slices, dried and stained with safranin and fast green ${ }^{25}$. The anatomical images were observed using a microscopic imaging system (BX51 + PD72 + IX71, OLYMPUS, Japan).

\section{Transcriptome analysis}

The total isolated RNAs were used for RNA-Seq on an Illumina HiSeq 2500. The sequencing library is prepared by random fragmentation of the cDNA sample, followed by $5^{\prime}$ and $3^{\prime}$ adapter ligation. Adapter-ligated fragments are then PCR amplified and gel purified. Sequences were screened for primer concatemers, weak signal and poly A/T tails. Low-quality reads were eliminated based on the score value (reads with $>30 \%$ of bases with quality score ( $Q$ value) of $<20$ ) and the remaining high quality reads were filtered for short reads below $50 \mathrm{bp}$. Adaptors were first trimmed, and then reads were further assembled by GS de novo assembler (v2.6) ${ }^{26}$. Singletons cleaning using Seqclean and lucy with a parameter of minimum length $100 \mathrm{bp}$ Illumina hiseq reads produced in paired-end formats (101 bp) were also assembled using the Trinity software package ${ }^{27}$. Reads were filtered and trimmed, and then mapped onto 'Dangshansuli' (P. bretschneideri Rehd.) coding sequences using the SOAP aligner ${ }^{28}$.

Clean reads were mapped using bowtie 1.1.2 to generate read alignments for each sample ${ }^{29}$. The gene expression level was calculated by fragments per kilobase of exon model per million mapped reads ${ }^{30}$. The RNA-Seq data of unpollinated ovaries were used as the controls. A false discovery rate of $<0.001$ and an absolute value of $\| \log _{2}$ ratiol $>1$ were used as the thresholds for the significance of differentially expressed genes (DEGs). Genes were annotated using the 'Dangshansuli' database (http://www. ncbi.nlm.nih.gov/genome/?term=pyrus) as a reference.

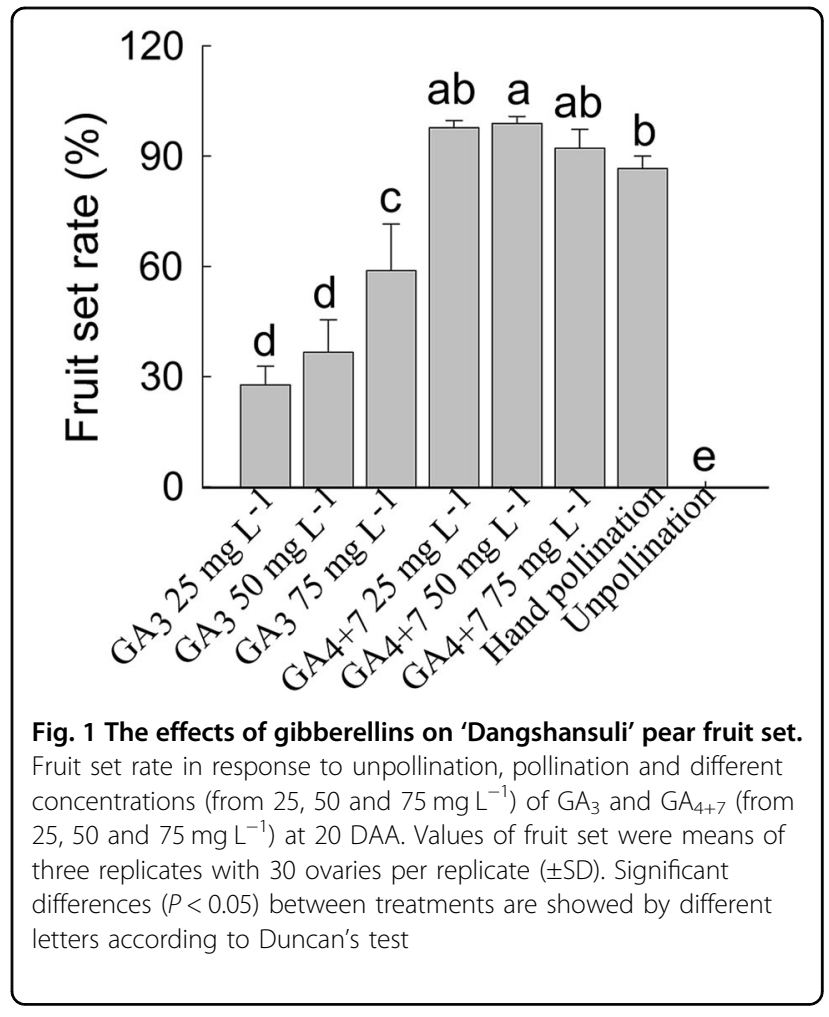

Three independent biological replications were sequenced and analysed.

\section{Quantitative real-time PCR validation of gene expression levels}

The qRT-PCR was performed on a Life Technologies (ABI) machine using the SYBR Premix Ex Taq Kit (TaKaRa, Dalian, China). The cDNA templates were reverse transcribed using total RNA extracted from ovaries of unpollinated, pollinated and $\mathrm{GA}_{4+7}$ treatments at 3, 9 and 14 DAA. Then, 11 selected genes were used to verify the expression results. Actin was used as the internal reference for the gene expression analysis. The use actin gene as internal reference is Actin 7 gene. All of the primers for selected genes were designed using Primer Premier 5.0 software, and are listed in Supplementary Table S2. The PCR reactions were carried out using an initial incubation at $95^{\circ} \mathrm{C}$ for $30 \mathrm{~s}$, and then 40 cycles of $95^{\circ} \mathrm{C}$ for $5 \mathrm{~s}$ and $60^{\circ} \mathrm{C}$ for $30 \mathrm{~s}$. All reactions were performed on three biological and three technical replicates. Relative quantification of specific mRNA levels was performed using the cycle threshold $(\mathrm{Ct}) 2^{-\Delta \Delta \mathrm{Ct}}$ method.

\section{MapMan analysis of DEGs}

To study the DEGs involved in carbohydrate and photosynthesis metabolism between pollinated and unpollinated, and $\mathrm{GA}_{4+7}$-treated and pollinated, we used the online web software Mercator to obtain the pear protein 


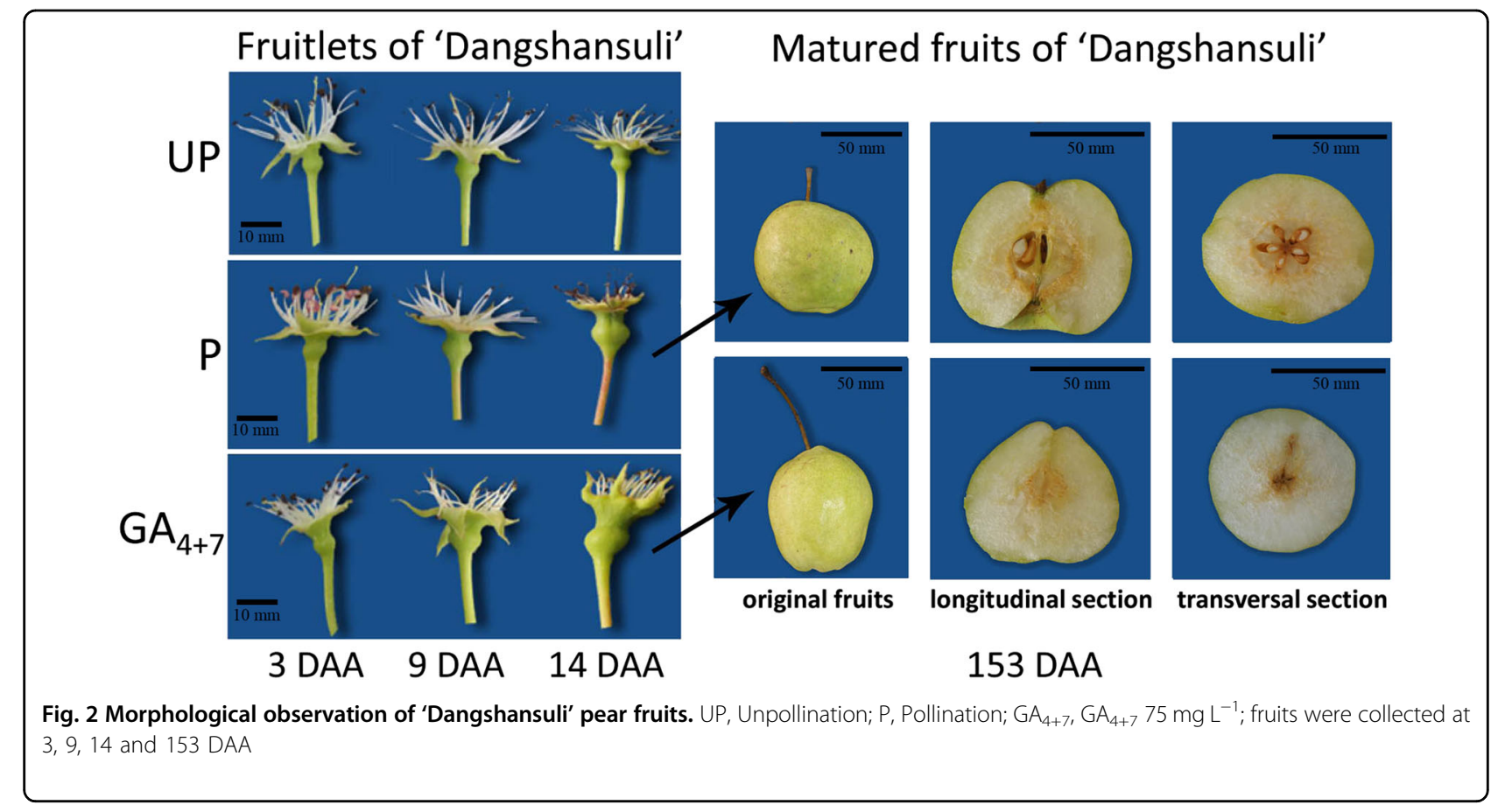

annotation mapping file for MapMan with the default parameters $^{31}$. MapMan was then used to classify the DEGs into functional categories ${ }^{32}$.

\section{Statistical methods}

The data were statistically analysed using an analysis of variance and tested for significant $(P<0.05)$ treatment differences using Duncan's test.

\section{Results}

\section{$\mathrm{GA}_{4+7}$ induced parthenocarpy in 'Dangshansuli'}

The fruit set rate reached $86.67 \%$ for hand pollination, 88.24-98.85\% for different concentrations of $\mathrm{GA}_{4+7}$ treatments, and no fruit set for unpollinated flowers. Although the highest set rate among the $\mathrm{GA}_{3}$ treatments was $58.89 \%$, which was lower than those of the $\mathrm{GA}_{4+7}$ treatments (Fig. 1), all of the $\mathrm{GA}_{3}$-treated fruits were eventually lost before harvest, while $\mathrm{GA}_{4+7}$ induced seedless mature fruits of a normal size. Thus, $\mathrm{GA}_{4+7}$, rather than $\mathrm{GA}_{3}$, may play an important role during the pear fruit set process.

\section{Morphological and histological observations in $\mathrm{GA}_{4+7^{-}}$ induced parthenocarpic fruits}

Morphological observations showed that unpollination, pollination and $\mathrm{GA}_{4+7}$ (From this point of the manuscript, the use of $\mathrm{GA}_{4+7}$ will refer to the $75 \mathrm{mg} \mathrm{L}^{-1}$ concentration) treated fruits at 3,9 and 14 DAA, mature fruits developed at 153 DAA. However, the unpollinated ovaries wilted at 14 DAA (Fig. 2). $\mathrm{GA}_{4+7}$ induced seedless fruits developed similar size as seeded fruits, but developed smaller core and elongated longitudinal diameter compared to seeded fruits.

Longitudinal sections of mesocarps exhibited $\mathrm{GA}_{4+7^{-}}$ induced cell expansion from 3 DAA (Fig. 3g) and formed larger cells than pollinated ovaries at 14 DAA (Fig. 3j). Cytological observations showed that apoptosis occurred in the unpollinated ovules and that locular cavities expanded (Fig. 4a), while both pollination and $\mathrm{GA}_{4+7}$ induced ovules development (Fig. 4d, g). Cell division process was activated during fruit set as well, transverse sections of mesocarps indicated that pollinated and $\mathrm{GA}_{4}$ +7 -treated ovaries developed thicker external mesocarps (EM, located between the vascular bundles and epidermis) with more cell layers than unpollinated ovaries (Fig. 4). The internal mesocarp (IM, between the vascular bundles and endocarp) did not show any differences among the treatments (Fig. 4). In addition, both pollinated and $\mathrm{GA}_{4}$ +7 -treated fruits developed larger vascular bundles compared with unpollinated ovaries (Fig. 4).

\section{Hormones involved in $\mathrm{GA}_{4+7}$-induced parthenocarpy}

The $\mathrm{GA}_{4+7}$ treatment dramatically and significantly increased $\mathrm{GA}_{1+3}$ and $\mathrm{GA}_{4+7}$ concentrations at $3 \mathrm{DAA}$. At 14. DAA, $\mathrm{GA}_{1+3}$ content of treated samples dropped to the same levels as unpollinated ovaries, while $\mathrm{GA}_{4+7}$ amount was still significantly higher. $\mathrm{GA}_{1+3}$ levels showed no significant differences between unpollination and pollination at same developmental stages, but pollination significantly increased the $\mathrm{GA}_{4+7}$ concentrations at both 3 and 14 DAA (Fig. 5a, c). IAA levels decreased all significantly from 0 to 14 DAA, while both $\mathrm{GA}_{4+7}$ and 

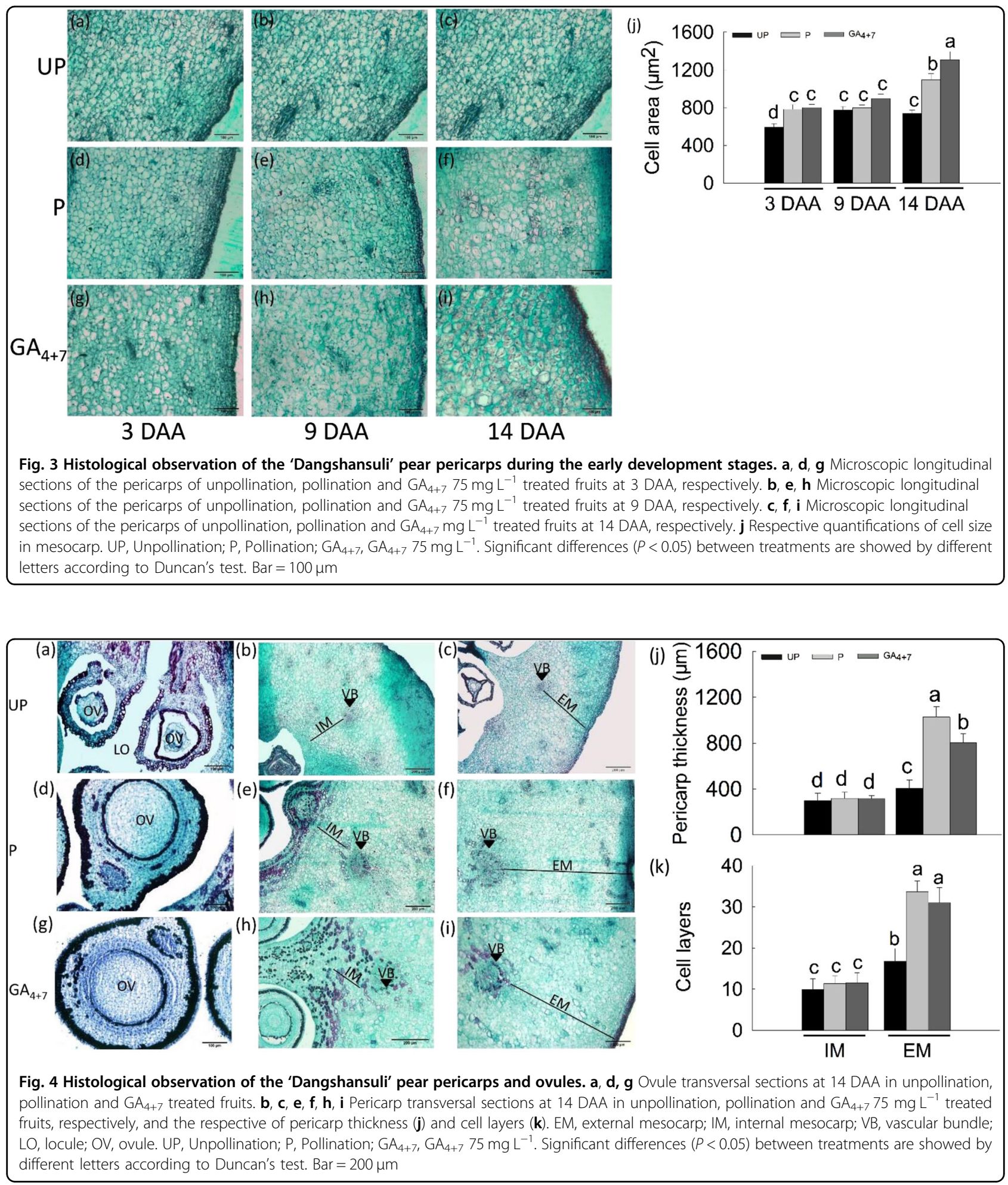

pollination treatments exhibited higher levels of IAA than unpollination at 3 DAA and 14 DAA (Fig. 5b). ABA levels significantly and dramatically increased in unpollinated flowers at 3 DAA and 14 DAA; however, both pollinated and GA-treated ovaries showed lower levels of $A B A$ at same development points. There is higher level of $A B A$ in $\mathrm{GA}_{4+7}$ treatment than pollination at both 3 and 14 DAA (Fig. 5d). 

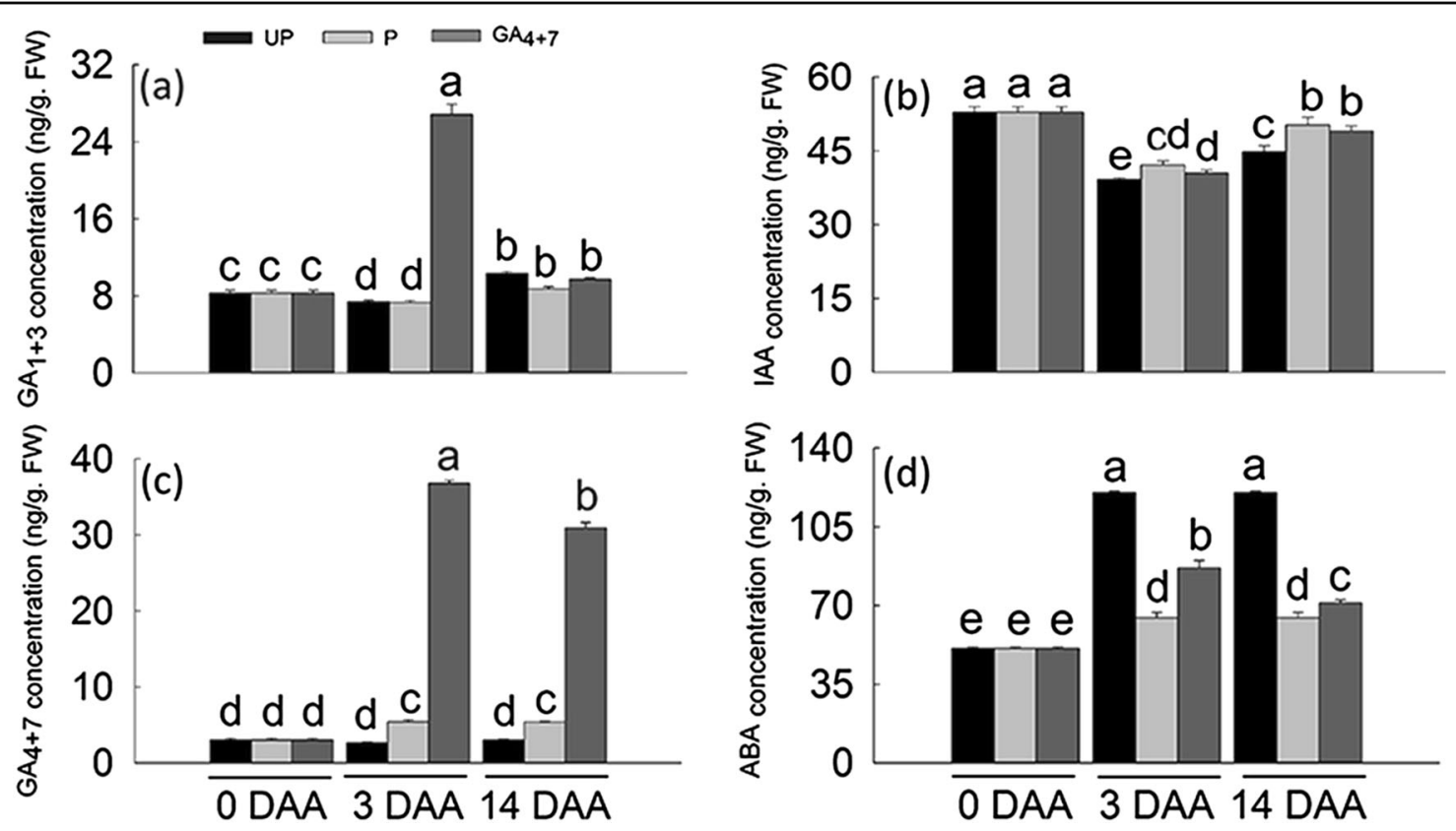

Fig. 5 Hormones measurement of 'Dangshansuli' pear fruits. The concentrations of plant hormones $G A_{1+3} \mathbf{a}, I A A \mathbf{b}$, GA $4+7$ c and $A B A \mathbf{d}$ in pear ovaries during early development stages ( 0,3 and $14 \mathrm{DAA})$. UP, Unpollination; P, Pollination; $\mathrm{GA}_{4+7}, \mathrm{GA}_{4+7} 75 \mathrm{mg} \mathrm{L}^{-1}$. Values of hormones were means of three biological and technical replicates $( \pm$ SD). Significant differences $(P<0.05)$ between treatments are showed by different letters according to Duncan's test

Transcriptome analysis of pear ovaries during fruit set

Based on our previous experiments, we found that at 14 DAA, the unpollinated flowers began to become withered, so we thought it was a key stage for fruit set. Besides, according to our pre-experiments, we found that hormone levels changed dramatically at 9 DAA, and 3 DAA was the earliest stage for fruit set, so we choose these three stages for further study, in order to more systematically clarify the mechanism of $\mathrm{GA}_{4+7}$ induced parthenocarpic fruit set. Ovaries for RNA-Seq were collected from unpollinated, pollinated and $\mathrm{GA}_{4+7}$-treated (without pollination) 'Dangshansuli' at 3, 9 and 14 DAA. Three independent biological replications were sequenced and analysed.

To investigate changes in the transcriptome during fruit set, we conducted Illumina HiSeq 2500 125PE sequencing of unpollinated, pollinated and $\mathrm{GA}_{4+7}$-treated ovaries at 3,9 and 14 DAA. There were at least 2.86 million raw reads for each sample, except for one sample $\left(\mathrm{GA}_{4}\right.$ +7_rep3, 65\% of the clean reads were mapped to the reference pear), $>75 \%$ of the clean reads were mapped to the reference pear ( $P$. bretschneideri Rehd.) genome (Supplementary Table S1). A false discovery rate $<0.001$, and $\log _{2}$ (ratio) $\mid>1$ were used as the thresholds to determine the significance of DEGs. To verify the RNASeq results, qRT-PCR was conducted for candidate genes. We choose 16 genes which was with low, average and high number of reads in $\mathrm{GA}_{4+7}$ treated fruits at 14 DAA, and seven important genes involved in gibberellin pathway were also included. The results exhibited in similar expression tendencies as the sequencing results, suggesting that the RNA-Seq data in this study are reliable (Supplementary Fig. S1).

Venn diagrams displayed the distribution of DEGs in pollinated and $\mathrm{GA}_{4+7}$-treated ovaries. At 3 DAA, 177 ( $8.1 \%$ of the total) upregulated and 140 (6.4\% of the total) downregulated genes were common to pollinated and $\mathrm{GA}_{4+7}$-treated ovaries. Following fruit development, the number of common DEGs increased, with 3029 (35.6\% of the total) upregulated and 2555 (30\% of the total) downregulated genes being common to the two treatments at 14 DAA (Supplementary Fig. S2).

\section{DEGs involved in GAs homoeostasis and signalling during fruit set}

$\mathrm{GA}_{4+7}$ treatment provided $>30 \mathrm{ng} / \mathrm{g}$. FW of exogenous $\mathrm{GA}_{4+7}$ (which is more than other treatments), so no more endogenous biosynthesis is needed, thus only entkaurenoic acid oxidases (KAOs) were induced. In addition to KAOs, pollination also induced ent-copalyl diphosphate synthase (CPS) (LOC103957280) and GA20ox2-like (LOC103960493) at 14 and 9 DAA, respectively. Genes encoding GA-inactivating GA2oxs showed similar expression trends between $\mathrm{GA}_{4+7}$ and 


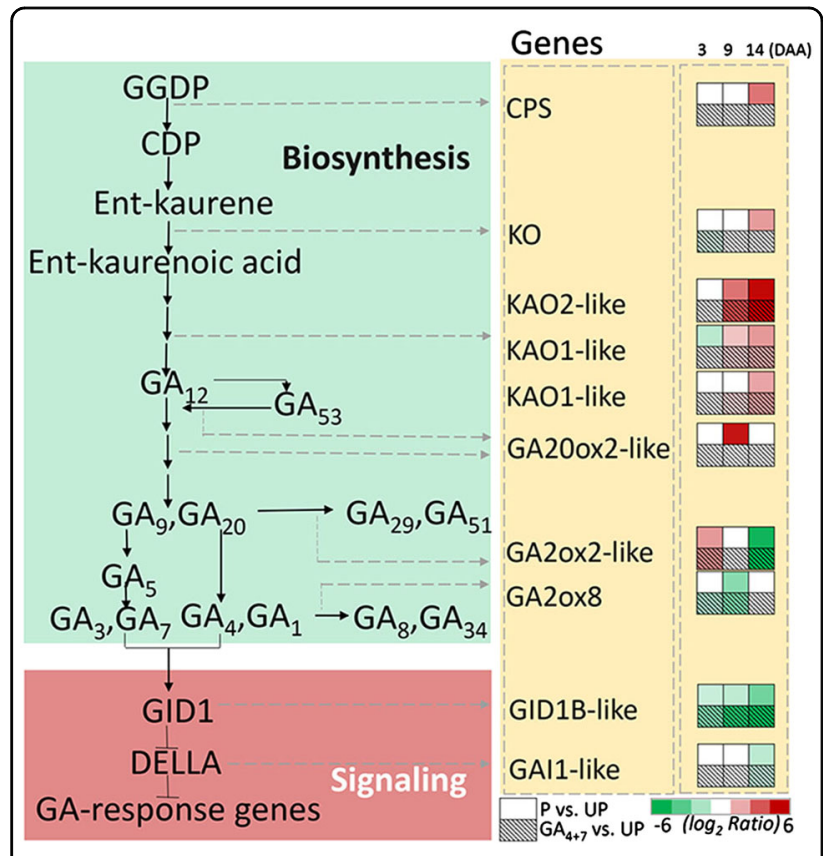

Fig. 6 Gibberellin metabolism and signalling pathways following pollination and $\mathrm{GA}_{4+7}$ treatments. The number of big rectangle (contain 6 small rectangles) represent copy number of each gene, and the upper small rectangles represent pollination treatment, and the below small squares represent the $\mathrm{GA}_{4+7} 75 \mathrm{mg} \mathrm{L}^{-1}$ treatment, and the small rectangles arrange from left to right represent the expression of genes at 3,9 and $14 \mathrm{DAA}$, respectively, with respect to unpollinated ovaries. UP, Unpollination; P, Pollination; $\mathrm{GA}_{4+7}, \mathrm{GA}_{4+7} 75$ $\mathrm{mg} \mathrm{L}^{-1}$. Different shades of red and green denote the extent of the change according to the colour bar provided ( $\log _{2}$ ratio of unpollnation treatment); white indicates no significantly change

pollinated treatments. Namely, at 3 DAA, GA2ox1-like (LOC103945984) was upregulated and then from 9 to 14 DAA exhibited downregulation. In addition, GA2ox8 (LOC103931224) in $\mathrm{GA}_{4+7}$-treated ovaries were downregulated at 3 DAA, while the downregulation in pollinated ovaries was delayed to $9 \mathrm{DAA}$. $\mathrm{GA}_{4+7}$ negatively regulated the expression of the GA receptor GID1 (LOC103938790), as well as pollination. The gene encoding DELLA protein GAI1-like (LOC103943039) was also downregulated in these two treatments at 14 DAA (Fig. 6).

\section{DEGs involved in auxin and ABA metabolism and their signalling pathways}

Four auxin efflux carrier components were upregulated in $\mathrm{GA}_{4+7}$-treated and pollinated ovaries. In particular, the auxin efflux carrier component 6 (LOC103951142) was upregulated more than eightfold ( $\log _{2}$ fold change). DEGs involved in auxin signal transduction were also modified, and ARF5-like (LOC103930094), ARF6 (LOC103951320), ARF18-like (LOC103962541) and ARF19-like

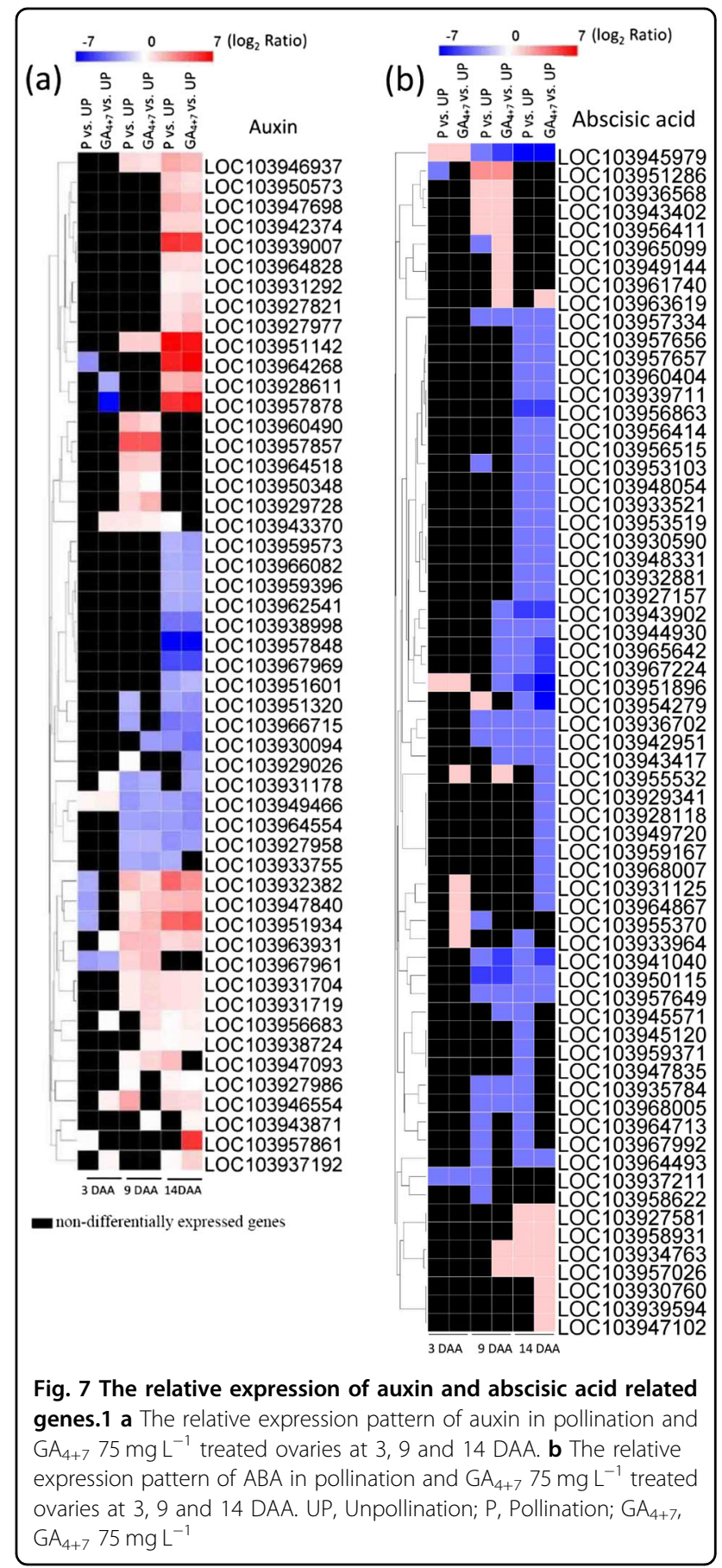

(LOC103959396) were downregulated in $\mathrm{GA}_{4+7}$-induced parthenocarpic fruits, as well as in the pollinated ovaries (Fig. 7a).

Two genes encoding 9-cis-epoxycarotenoid dioxygenase (NCED3) were significantly downregulated in $\mathrm{GA}_{4+7^{-}}$ treated and pollinated ovaries. In particular, one NCED3 (LOC103945979) was downregulated more than fivefold ( $\log _{2}$ fold change). A variety of DEGs involved in the ABA signalling pathway were repressed, and 40 protein 


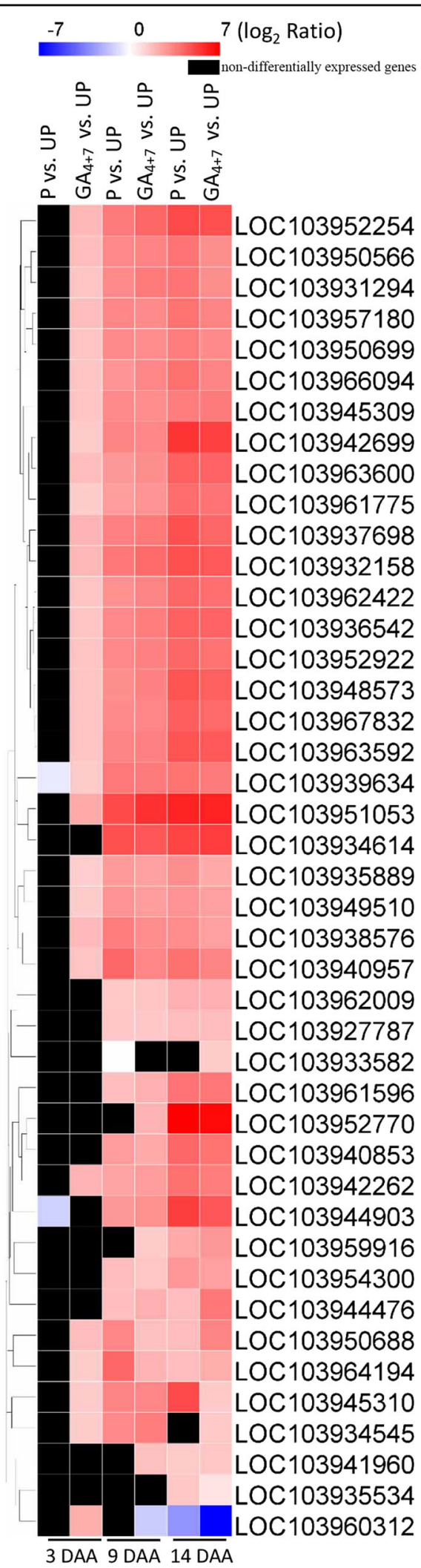

Fig. 8 The expression profiles of cyclin and expansin family genes. UP, Unpollination; P, Pollination; $\mathrm{GA}_{4+7}, \mathrm{GA}_{4+7} 75 \mathrm{mg} \mathrm{L}^{-}$ phosphatase 2Cs were modified during the fruit set process (Fig. 7b). Specific information of genes involved in Fig. 7 was exhibited in Supplementary Tables S6 and S7.

Cell cycle and expansion-related genes were upregulated during fruit set

Cell division-related and cell wall-related genes were upregulated in $\mathrm{GA}_{4+7}$-induced parthenocarpic fruits, as well as in pollinated ovaries. In total, there were 31 upregulated cyclin genes in $\mathrm{GA}_{4+7}$-induced ovaries, most of which were significantly upregulated at 3 DAA. However, the upregulation was delayed to $9 \mathrm{DAA}$ in pollinated ovaries. Among these cyclins, a U4-1-like cyclin (LOC103952770) was upregulated more than sixfold $\left(\log _{2}\right.$ fold change) in both $\mathrm{GA}_{4+7}$-treated and pollinated ovaries at 14 DAA. Nine G2/mitotic-specific cyclins were upregulated in $\mathrm{GA}_{4+7}$-induced parthenocarpic fruits from 3 DAA, while their upregulation in pollinated ovaries was delayed to 9 DAA. During fruit development, the elevated levels of these G2/mitotic-specific cyclins increased, and at 14 DAA, all of these $\mathrm{G} 2 /$ mitotic-specific cyclin genes were upregulated more than threefold ( $\log _{2}$ fold change) in parthenocarpic fruits, as well as in pollinated ovaries. In addition, two cyclin-dependent kinase (CDKs) (LOC103952922 and LOC103961775) genes were upregulated in $\mathrm{GA}_{4+7}$-induced parthenocarpic fruits from 3 DAA, while the upregulation in pollinated ovaries was delayed to 9 DAA. RNA-Seq results showed that 10 expansin genes were upregulated, and except for expansin-like B1(LOC103960312), in both $\mathrm{GA}_{4+7^{-}}$ induced parthenocarpic and pollinated ovaries, especially expansin-A15 (LOC103951053), expansin-B3-like (LOC103934614) and expansin-A6-like (LOC103944903), which were upregulated more than fourfold $\left(\log _{2}\right.$ fold change) (Fig. 8). In total, 103 cell wall-related DEGs were involved in $\mathrm{GA}_{4+7}$-induced parthenocarpic fruits at 3 DAA, and 72 cell wall-related genes were changed by pollination. At later stages, $\sim 140$ cell wall-related genes were significantly modified in parthenocarpic and pollinated ovaries (Supplementary Table S3).

\section{Photosynthetic processes and sugar metabolism were modified during fruit set}

To analyse carbohydrate and photosynthesis-related metabolisms, DEGs were grouped based upon their biological functions using MapMan. Results showed that the number of DEGs involved in carbohydrate and photosynthesis metabolisms increased with time going (from 3 to 14 DAA) (Fig. 9, Supplementary Fig. S3). Photosynthesis-related genes were activated, with 59 (Supplementary Fig. S3c) and 45 (Fig. 9a) upregulated DEGs at 9 and 14 DAA, respectively, in pollinated ovaries, and 55 (Supplementary Fig. S3d) and 61 (Fig. 9b) upregulated DEGs in parthenocarpic fruit at 9 and 14 DAA, 


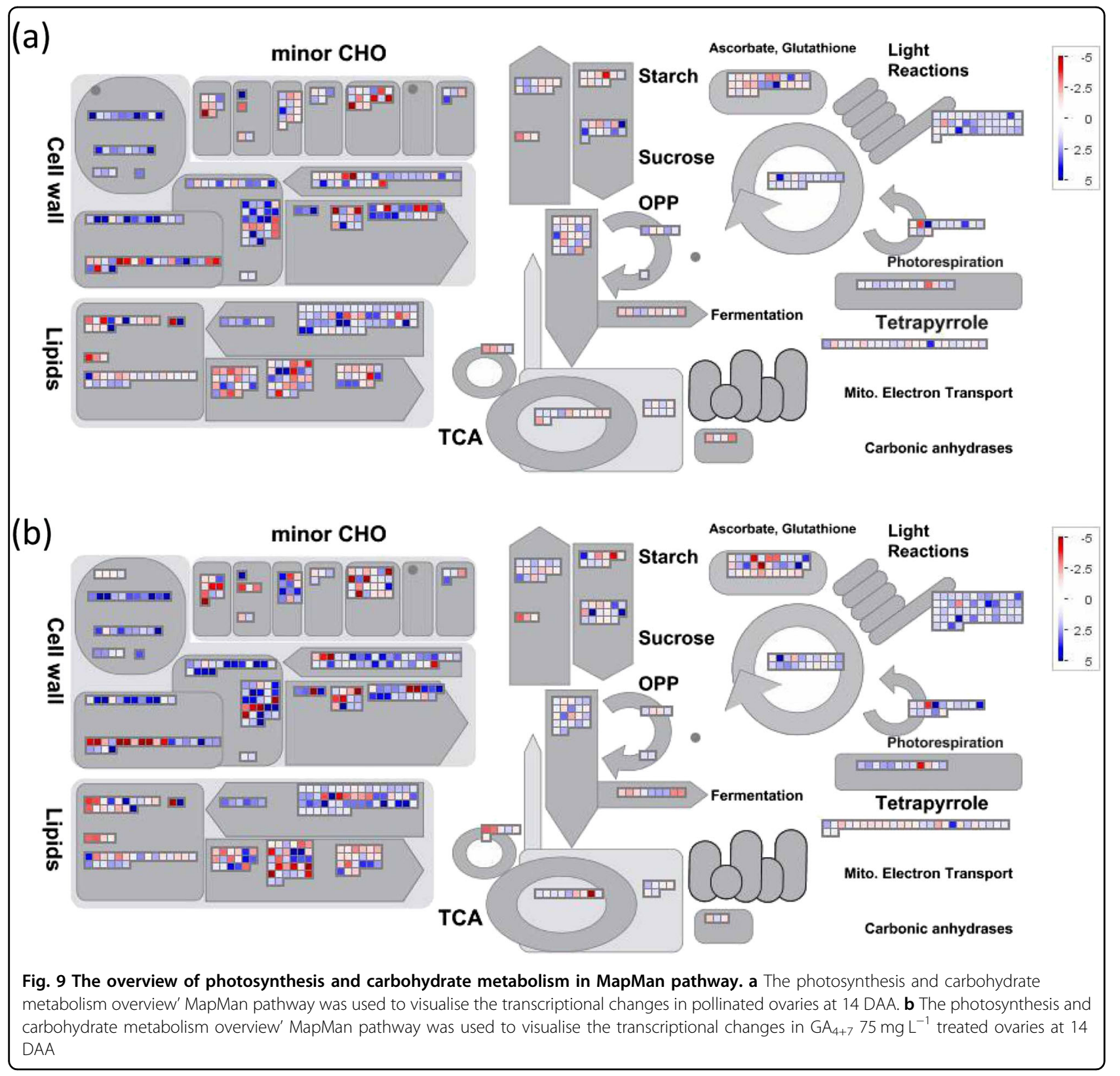

respectively. At 3 DAA, mainly cell wall-related genes were induced in both pollination and $\mathrm{GA}_{4+7}$-treated ovaries. Minor $\mathrm{CHO}$, Lipids, TCA and light reactions processes were activated at 9 DAA, especially for light reactions process, all of DEGs which was involved in this process were upregulated (Supplementary Fig. S3). There were more DEGs involved in these processes at 14 DAA, and most of them were upregulated in both pollination and $\mathrm{GA}_{4+7}$-treated fruits.

Four sucrose synthases (LOC103935320, LOC103950289, LOC103950290 and LOC103950291) were upregulated in parthenocarpic and pollinated ovaries at 14 DAA. Genes encoding elements of the sugar degradation process also changed after $\mathrm{GA}_{4+7}$-treatment and pollination. Three sucrose hydrolases (LOC103959831, LOC103961960 and LOC103963401) and two alpha amylases (LOC103950868 and LOC103955697) were induced in both parthenocarpic and pollinated ovaries. Two invertases ( $L O C 103961960$ and LOC103963401) were upregulated in $\mathrm{GA}_{4+7}$-induced parthenocarpic fruits at 9 and 14 DAA, pollination showed similar expression patterns. In particular, the expression of LOC103961960 was upregulated about eightfold in both parthenocarpic and pollinated ovaries at 14 DAA. Genes involved in cell wall synthesis, such as UDP-glucose 4, 6-dehydratase (LOC103966239 and 
LOC103947469), UDP-glucose 6-dehydrogenase (LOC103930880, LOC103947238 and LOC103931361) and UDP-glucuronic acid decarboxylases (LOC103944949, LOC103948978, LOC103928376, LOC103928424 and LOC103930040) were significantly upregulated in parthenocarpic and pollinated ovaries at 14 DAA, while the expression of three other genes (LOC103948402, LOC103963541 and LOC103965769) belonging to the UDP-glucuronic acid decarboxylase family were only found in $\mathrm{GA}_{4+7}$-induced parthenocarpic fruits at 14 DAA (Supplementary Table S4).

\section{Transcription factors (TFs) involved in fruit set}

TFs play crucial roles in regulating many developmental processes. There were 124, 240 and 449 DEGs at 3, 9 and 14 DAA, respectively, encoding TFs in $\mathrm{GA}_{4+7}$-induced parthenocarpic ovaries, and 59, 199 and 385 DEGs encoding TFs in pollinated ovaries at 3, 9 and 14 DAA, respectively (Supplementary Fig. S4). There were 32, 139 and 329 differentially expressed TFs showed similar expression patterns between $\mathrm{GA}_{4+7}$ and pollination treatments at $3 \mathrm{DAA}, 9$ and $14 \mathrm{DAA}$, respectively, which shows that the number of TFs increased with time going. Besides, 91, 165 and 177 differentially expressed TFs exhibited differential expression pattern between $\mathrm{GA}_{4+7}$ and pollination treated ovaries at 3 DAA, 9 and 14 DAA, respectively. The majority of changed TFs belong to the bHLH, MYB, NAC and WRKY families (Supplementary Fig. S4).

MADS-box genes may play important regulatory roles during fruit development ${ }^{33}$. AGL19 is one of the MADSbox family genes, both $\mathrm{GA}_{4+7}$ and pollination treatments repressed the expression of AGL19 (LOC103952886) at 9 DAA. Besides, AGL9 (LOC103961438) was only downregulated in $\mathrm{GA}_{4+7}$-treated ovaries at 14 DAA. In our analysis, two DEFs (LOC103938026 and LOC103966740) were significantly repressed in parthenocarpic ovaries at 14 DAA, while only one DEF (LOC103938026) was significantly downregulated in pollinated ovaries.

\section{Discussion}

Phytohormones play a crucial role in regulating fruit set, and exogenous applications of plant hormones can induce artificial parthenocarpy ${ }^{3} . \mathrm{GA}_{3}$ can induce parthenocarpic fruits in several plants, including tomato and grape ${ }^{34,35}$. In our study, exogenous application of $\mathrm{GA}_{4+7}$, rather than $\mathrm{GA}_{3}$, induced parthenocarpic pear fruit, although exogenous applications of $\mathrm{GA}_{4+7}$ could increase the $\mathrm{GA}_{1+3}$ content. Pollination increased $\mathrm{GA}_{4+7}$ levels, but barely affected the $\mathrm{GA}_{1+3}$ content. Thus, $\mathrm{GA}_{4+7}$, rather than $\mathrm{GA}_{3}$, may play the main role in regulating 'Dangshansuli' fruit set. Pollination promoted the expression of CPS (except for at $9 \mathrm{DAA}), K O, K A O$ s and GA20oxs, which synthesise bioactive $\mathrm{GA}$, while $\mathrm{GA}_{4+7}$ only promoted the expression of KAOs. GA2oxs, which function to deactivate bioactive GA, most of which were downregulated in parthenocarpic ovaries, as well as in pollinated ovaries. Both $\mathrm{GA}_{4+7}$ and pollination repressed the expression of GID1B-like from 9 DAA. At 14 DAA, the expression levels of GAI1-like were also repressed, and pollination resulted in a similar expression pattern. Thus, $\mathrm{GA}_{4+7}$ barely changed the mRNA levels of the encoded biosynthetic GA genes, since GA content was already high to support fruit set processes, while mainly influencing GAresponse genes.

Auxins also play key roles during fruit set, and the application of IAA was shown to induce cell division in the tomato pericarp ${ }^{36} . \mathrm{GA}_{4+7}$ did not increase the IAA concentration, but it promoted auxin efflux carrier components (1c, 1b and 6) expression levels, which was consistent with pollination.

ABA inhibit cell division by inducing ICK1, a $C D K$ inhibitor $^{37}$, and ABA levels were relatively high in unpollinated ovaries and decreased after pollination. An important $\mathrm{ABA}$ biosynthesis gene in tomato, LeNCED1 was repressed after pollination ${ }^{38}$. Both $\mathrm{GA}_{4+7}$ and pollination treatments decreased $\mathrm{ABA}$ accumulation in ovaries compared with unpollination, and NCED3 and NCED5 were significantly downregulated in these two treatments.

Thus, GA coordinates with IAA and the ABA balance, promoting cell division and expansion, thus stimulating fruit set and development.

Pollination and the following double-fertilisation occurrences in the carpel cause a coordinated sequence of cell division, expansion and differentiation events that result in fruit set and maturity ${ }^{39}$. Exogenous applications of $\mathrm{GA}_{4+7}$ promoted the development of unpollinated ovaries, while the unpollinated ovaries ceased to grow and ovules aborted at 14 DAA. Serrani et al. ${ }^{34}$ also found that unfertilised ovules degenerated in the former case in tomatoes. $\mathrm{GA}_{4+7}$-treatments produced larger cells than pollination in the mesocarp, which was consistent with GA inducing larger cells than pollination in tomato ${ }^{34}$. However, $\mathrm{GA}_{4+7}$ promoted external mesocarp division because $\mathrm{GA}_{4+7}$-induced parthenocarpic ovaries had more cell layers than those of the unpollinated ovaries, but similar cell layers as the pollinated ovaries.

Transcriptome data showed that the amounts of cell cycle and cell wall-related genes were modified by $\mathrm{GA}_{4+7}$ treatments, suggesting the importance of cell division and cell expansion in fruit set and development. The cell cycle is mainly regulated by two key classes of regulators, $C D K \mathrm{~s}$ and cyclins [8]. A-, B- and D-type cyclins mainly regulate the $\mathrm{S}$ and $\mathrm{G} 2 / \mathrm{M}$ phases ${ }^{8,40,41}$, and B-type $C D K$ s are specifically expressed in $G 2$ and $M$ phase ${ }^{42}$. Our study showed that 33 DEGs, including B-type $C D K s$, A-, B-, Dand U-cyclins and G2/mitotic-specific cyclins, were positively regulated by $\mathrm{GA}_{4+7}$ or pollination during fruit 
set, suggesting that activated $\mathrm{G} 2 / \mathrm{M}$ phase regulators are available for cell proliferation. A previous study showed that 14 cell cycle genes were positively associate with cell proliferation during apple fruit set and development ${ }^{43}$.

The cell wall is comprised of cellulose, hemicellulose and pectin, as well as proteins, which influence cell expansion $^{44}$. Expansin $A(E X P A)$ and $B(E X P B)$ belong to the $\alpha$ - and $\beta$-expansin families, respectively, and many of their members have the ability to induce rapid cell expansion ${ }^{45}$. In our study, EXPB3-like and five EXPAs were significantly upregulated in $\mathrm{GA}_{4+7}$-induced parthenocarpic fruits. Glucanases, other wall hydrolases, and $X E T$ s affected cell enlargement by regulating cell expansion activities ${ }^{46}$. In our analysis, two endo-1,3;1,4-beta-Dglucanase-like genes had decreased expression levels, while four glucomannan 4-beta-mannosyltransferase genes had significantly increased expression levels in parthenocarpic and pollinated ovaries. Xyloglucan endotransglucosylase/hydrolase $(X T H)$ enzymes play crucial roles in promoting cell expansion by disassembling xyloglucan $^{47}$, and the expression of several $X T H \mathrm{~s}$ was increased, with $X T H 8, X T H 9, X T H 31$ and $X T H 32$ being significantly upregulated in $\mathrm{GA}_{4+7}$-induced parthenocarpic ovaries and pollinated ovaries. A variety of cell cycle and cell wall-related genes were significantly upregulated in our analysis, suggesting that these categories of genes also take part in fruit set. UDP-glucuronic acid, a nucleotide sugar that is a precursor of the cell wall, is formed through the activity of UDP-glucose dehydrogenase, which catalyses UDP-glucose into UDPglucuronic $\operatorname{acid}^{48}$. Our analysis showed that both UDP- glucose dehydrogenase and UDP-glucuronic acid decarboxylases were significantly increased in parthenocarpic and pollinated ovaries. This result was consistent with pericarps undergoing rapid cell division and expansion periods, and the activation of cell wall synthesis.

Photosynthesis provides necessary nutrition for fruit and seed set, and deficient photosynthesis is a primary driver of flower, fruit and seed abortion ${ }^{1}$. Antisense silencing of SIIAA9 induced parthenocarpic tomatoes, which had upregulated expression levels photosynthesisassociated genes ${ }^{49}$, and our analysis corroborated these results. According to the MapMan analysis, the expression levels of photosynthesis-associated genes were upregulated in $\mathrm{GA}_{4+7}$-induced parthenocarpic pear ovaries, and pollinated ovaries showed similar results. Plant growth relies on photosynthesis products, mainly in the form of sucrose in most crop species ${ }^{1}$, and invertase cleaves the sucrose to hexose, which promotes fruit and seed set $^{1}$. Our analysis showed that the DEGs involved in sucrose degradation were upregulated in parthenocarpic ovaries, as well as pollinated ovaries. The genes encode enzymes associated with the decomposition of sucrose, suggesting that a high level of energy is demanded during fruit set.

The present study clarified that MADs-box family genes play roles in regulating fruit set ${ }^{21,50}$. Class B MADs-box genes control petal and stamen development, and the loss-of-function of a class B MADs-box results in parthenocarpy in apple, and DEFICIENS (DEF) belongs to class B MADs-box family ${ }^{21}$. SIDEF functions as a repressor in ovules and inhibits the development of

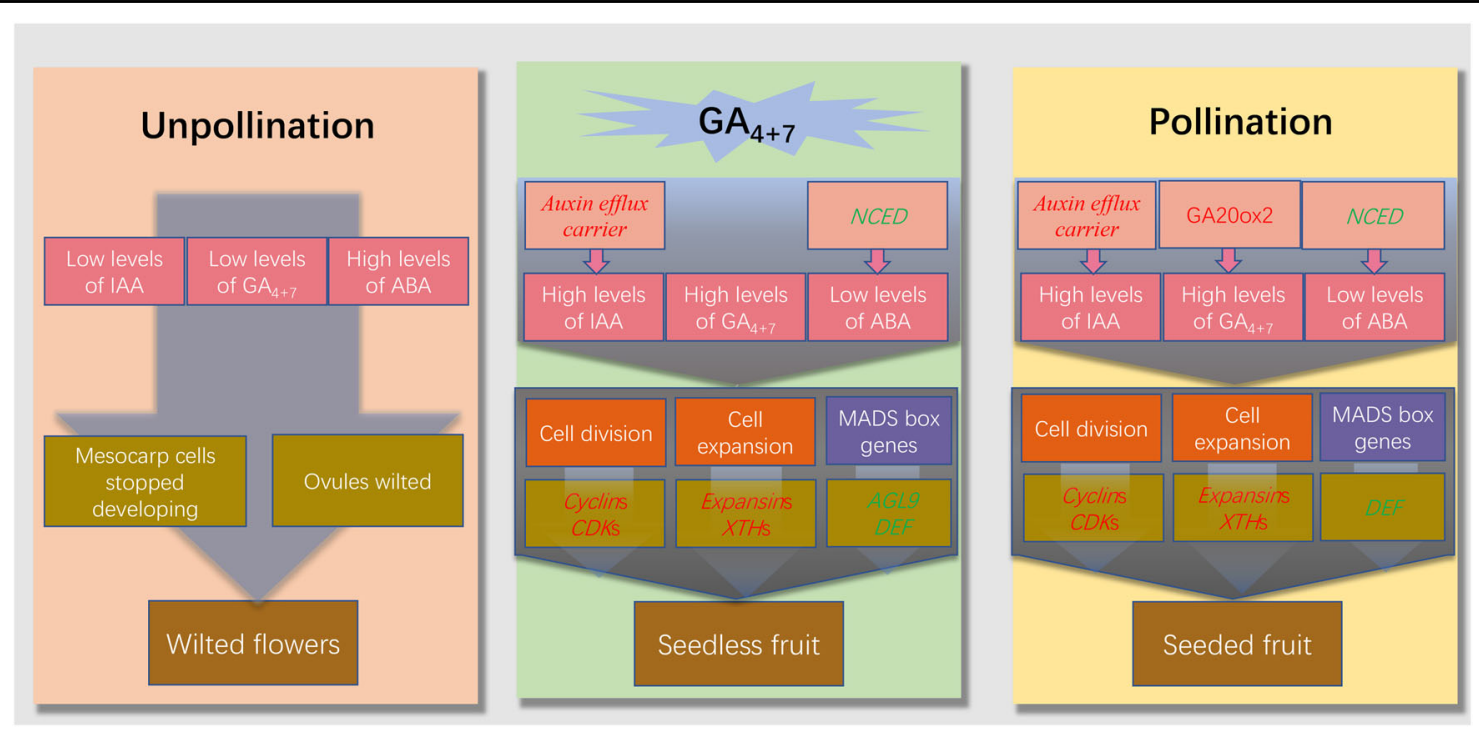

Fig. 10 The mechanistic model of fruit set. Gene names in red font represent related genes were upregulated, instead, those in green front represent related genes were downregulated 
ovaries in unpollinated tomatoes, and it was upregulated before or during anthesis in the wild type, but not in the pat mutant ${ }^{51}$. In our analysis, DEF (LOC103966740) was significantly repressed in parthenocarpic and pollinated ovaries. The class E MADS-box genes are essential for all floral whorls involved in specifying organ identities, and $A G L 9$ is an E class gene ${ }^{52,53}$. Our studies exhibited that $A G L 9$ was repressed in parthenocarpic fruits.

\section{Conclusions}

In summary, our studies found that $\mathrm{GA}_{4+7}$, but not $\mathrm{GA}_{3}$, induced pear parthenocarpy, which was consistent with pollination increasing the $\mathrm{GA}_{4+7}$ contents but not $\mathrm{GA}_{1+3}$. $\mathrm{GA}_{4+7}$ maintained normal cell growth in mesocarps, as well as pollination, while unpollinated ovaries ceased growing and then shrunk. Genes involved in cell cycle and cell expansion were upregulated in $\mathrm{GA}_{4+7^{-}}$ induced parthenocarpic pear fruit. RNA-Seq results also revealed that the photosynthesis and sugar metabolism processes were activated, suggesting that they may also take part in fruit set. $\mathrm{GA}_{4+7}$ did not increase the IAA level but promoted its transport through gene expression. $\mathrm{GA}_{4}$ +7 repressed the ABA biosynthetic gene NCED, resulting in lower $\mathrm{ABA}$ levels in parthenocarpic ovaries. $\mathrm{GA}_{4+7^{-}}$ repressed genes (MADS-box family genes $A G L 9$ and $D E F$ ) were directly related to parthenocarpy. The model presented in Fig. 10 represented that application of $\mathrm{GA}_{4+7}$ to unpollinated ovaries may promote the hormonal balance, photosynthesis, sugar metabolism, the cell cycle and cell expansion, and also repress $A G L 9$ and DEF expressions, resulting in fruit set.

\section{Acknowledgements}

This work was supported by the China Agriculture Research System (CARS-2940) and Weinan Experimental Station foundation of Northwest A\&F University.

\section{Conflict of interest}

The authors declare that they have no conflict of interest.

Received: 2 July 2017 Revised: 7 November 2017 Accepted: 28 November 2017

Published online: 03 January 2018

\section{References}

1. Ruan, Y. L., Patrick, J. W., Bouzayen, M., Osorio, S. \& Fernie, A. R. Molecular regulation of seed and fruit set. Trends Plant Sci. 17, 656-665 (2012).

2. Ramírez, F. \& Davenport, T. L. Apple pollination: a review. Sci. Hortic. 162, 188-203 (2013).

3. Gillaspy, G., Ben-David, H. \& Gruissem, W. Fruits: a developmental perspective. Plant Cell 5, 1439-1451 (1993).

4. Ding, J. G. et al. Cytokinin-induced parthenocarpic fruit development in tomato is partly dependent on enhanced gibberellin and auxin biosynthesis. PLOS ONE 8, e70080 (2013).

5. Mesejo, C., Reig, C., Martínez-Fuentes, A. \& Agustí, M. Parthenocarpic fruit production in loquat Eriobotrya japonica Lindl by using gibberellic acid. Sci. Hortic. 126, 37-41 (2010).
6. Niu, Q. F. et al. Effects of exogenous application of $\mathrm{GA}_{4+7}$ and N-2-chloro-4pyridyl-N'-phenylurea on induced parthenocarpy and fruit quality in Pyrus pyrifolia 'Cuiguan'. Plant Growth Regul. 76, 251-258 (2015).

7. Sugiyama, K., Kami, D. \& Muro, T. Induction of parthenocarpic fruit set in watermelon by pollination with bottle gourd Lagenaria siceraria Molina Standl pollen. Sci. Hortic. 171, 1-5 (2014).

8. Mesejo, C., Yuste, R., Reig, C. \& Martínez-Fuente, A. Gibberellin reactivates and maintains ovary-wall cell division causing fruit set in parthenocarpic Citrus species. Plant Sci. 247, 13-24 (2016).

9. Nitsch, J. P. Plant hormones in the development of fruits. Q. Rev. Biol. 27, 33-57 (1952).

10. de Jong, M., Wolters-Arts, M., Feron, R., Mariani, C. \& Vriezen, W. H. The Solanum lycopersicum auxin response factor 7 SIARF7 regulates auxin signaling during tomato fruit set and development. Plant J. 57, 160-170 (2009).

11. Du, L. et al. SmARF8, a transcription factor involved in parthenocarpy in eggplant. Mol. Genet. Genom. 291, 93-105 (2016).

12. Wang, $\mathrm{H}$. et al. The tomato Aux/IAA transcription factor IAA9 is involved in fruit development and leaf morphogenesis. Plant Cell 17, 2676-2692 (2005).

13. Serrani, J. C., Carrera, E., Ruiz-Rivero, O. \& Gallego-Giraldo, L. Inhibition of auxin transport from the ovary or from the apical shoot induces parthenocarpic fruit-set in tomato mediated by gibberellins. Plant Physiol. 153, 851-862 (2010).

14. Fos, M., Proaño, K., Nuezc, F. \& García-Martínez, J. L. Role of gibberellins in parthenocarpic fruit development induced by the genetic system pat-3/pat-4 in tomato. Plant Physiol. 111, 545-550 (2001).

15. Greco, M., Chiappetta, A., Bruno, L. \& Bitonti, M. B. Posidonia oceanica cadmium induces changes in DNA methylation and chromatin patterning. J. Exp. Bot 63, 695-709 (2012).

16. Martinez-Bello, L., Moritz, T. \& Lopez-Diaz, I. Silencing C19-GA 2-oxidases induces parthenocarpic development and inhibits lateral branching in tomato plants. J. Exp. Bot. 66, 5897-5910 (2015).

17. Marti, C. et al. Silencing of DELLA induces facultative parthenocarpy in tomato fruits. Plant J. 52, 865-876 (2007)

18. Harberd, N. P., Belfield, E. \& Yasumura, Y. The angiosperm gibberellin-GID1DELLA growth regulatory mechanism: how an "Inhibitor of an Inhibitor" enables flexible response to fluctuating environments. Plant Cell 21, 1328-1339 (2009).

19. Hirano, $\mathrm{K}$. et al. Characterization of the molecular mechanism underlying gibberellin perception complex formation in rice. Plant Cell 22, 2680-2696 (2010).

20. Ampomah-Dwamena, C. Down-Regulation of TM29, a Tomato SEPALLATA homolog, causes parthenocarpic fruit development and floral reversion. Plant Physiol. 130, 605-617 (2002).

21. Yao, J. L., Dong, Y. H. \& Morris, B. A. M. Parthenocarpic apple fruit production conferred by transposon insertion mutations in a MADS-box transcription factor. Proc. Natl Acad. Sci. USA 98, 1306-1311 (2001).

22. Klap, $C$. et al. Tomato facultative parthenocarpy results from SIAGAMOUS-LIKE 6 loss of function. Plant Biotechnol. J. 155, 634 (2017).

23. Yang, J. C., Zhang, J. H., Wang, J. Q., Zhu, Q. S. \& Liu, L. J. Water deficit-induced senescence and its relationship to the remobilization of pre-stored carbon in wheat during grain filling. Agro J. 93, 196-206 (2001).

24. Henwood, A. Formalin pigment from formaldehyde-acetic acid-alcohol fixed tissues? J. Histotechnol. 33, 109-111 (2010).

25. in, Z. Q. et al. AtCDC5 regulates the $\mathrm{G} 2$ to $M$ transition of the cell cycle and is critical for the function of Arabidopsis shoot apical meristem. Cell Res. 17, 815-828 (2007).

26. Matilla, M. A. \& Salmond, G. P. C. Complete genome sequence of serratia plymuthica bacteriophage Ф MAM1. J. Virol. 86, 13872-13873 (2012).

27. Haas, B. J. et al. De novo transcript sequence reconstruction from RNA-Seq reference generation and analysis with Trinity. Nat. Protoc. 8, 1494-1512 (2013).

28. Li, R. et al. SOAP2: an improved ultrafast tool for short read alignment Bioinformatics 25, 1966-1967 (2009)

29. Langmead, B., Trapnell, C., Pop, M. \& Salzberg, S. L. Ultrafast and memoryefficient alignment of short DNA sequences to the human genome. Genome Biol. 10, R25 (2009).

30. Wapinski, O. L. et al. Hierarchical mechanisms for direct reprogramming of fibroblasts to neurons. Cell 155, 621-635 (2013).

31. Lohse, $\mathbf{M}$. et al. Mercator: a fast and simple web server for genome scale functional annotation of plant sequence data. Plant Cell Environ. 37 1250-1258 (2014) 
32. Thimm, O. et al. Mapman: a user-driven tool to display genomics data sets onto diagrams of metabolic pathways and other biological processes. Plant $\mathrm{J}$. 37, 914-939 (2004).

33. Masiero, S., Colombo, L., Grini, P. E., Schnittger, A. \& Kater, M. M. The emerging importance of type I MADS box transcription factors for plant reproduction. Plant Cell 23, 865-872 (2011).

34. Serrani, J. C., Fos, M., Atarés, A. \& García-Martínez, J. L. Effect of gibberellin and auxin on parthenocarpic fruit growth induction in the cV micro-tom of tomato. J. Plant Growth Regul. 26, 211-221 (2007).

35. Jung, C. J. et al. Gibberellin application at pre-bloom in grapevines downregulates the expressions of VVIAA9 and VVARF7, negative regulators of fruit set initiation, during parthenocarpic fruit development. PLOS ONE 9, e95634 (2014).

36. Liu, X. et al. The role of gibberellins and auxin on the tomato cell layers in pericarp via the expression of ARFs regulated by miRNAs in fruit set. Acta Physiol. Plant 38, 77 (2016).

37. Wang, $\mathrm{H}$. et al. ICKI, a cyclin-dependent protein kinase inhibitor from Arabidopsis thaliana interacts with both $C d c 2 a$ and $C y c D 3$, and its expression is induced by abscisic acid and its expression is induced by abscisic acid. Plant $\mathrm{J}$. 15, 501-510 (1998).

38. Nitsch, L. M. et al. Abscisic acid levels in tomato ovaries are regulated by LeNCED1 and SICYP707A. Planta 229, 1335-1346 (2009).

39. Vivian-Smith, A. \& Koltunow, A. M. Genetic analysis of growth regulatorinduced parthenocarpy in Arabidopsis. Plant Physiol. 121, 437-451 (1999).

40. Beemster, G. T. S. et al. Genome-wide analysis of gene expression profiles associated with cell cycle transitions in growing organs of Arabidopsis. Plant. Physiol. 138, 734-743 (2005).

41. InzéD, V. L. D. Cell cycle regulation in plant development. Annu. Rev. Genet. 40, 77-105 (2006).

42. Breyne, P. et al. Transcriptome analysis during cell division in plants. PNAS 99 14825-14830 (2002).
43. Malladi, A. \& Johnson, L. K. Expression profiling of cell cycle genes reveals key facilitators of cell production during carpel development, fruit set, and fruit growth in apple Malusxdomestica Borkh. J. Exp. Bot. 62, 205-219 (2011).

44. Bashline, L., Lei, L., Li, S. \& Gu, Y. Cell wall, cytoskeleton, and cell expansion in higher plants. Mol. Plant 7, 586-600 (2014).

45. Kende, H., Bradford, K., Brummell, D., Cho, H. \& Cosgrove, D. Nomenclature for members of the expansin superfamily of genes and proteins. Plant Mol. Biol. 55, 311-314 (2004).

46. Cosgrove, D. J. Relaxation in a high-stress envirsnment: the molecular bases of extensible cell walls and cell enlargement. Plant Cell 9, 1031-1041 (1997).

47. Atkinson, R. G., Johnston, S. L., Yauk, Y., Sharma, N. N. \& Schröder, R. Analysis of xyloglucan endotransglucosylase/hydrolase XTH gene families in kiwifruit and apple. Postharvest Biol. Tec. 51, 149-157 (2009).

48. Klinghammer, M. \& Tenhaken, R. Genome-wide analysis of the UDP-glucose dehydrogenase gene family in Arabidopsis, a key enzyme for matrix polysaccharides in cell walls. J. Exp. Bot. 58, 3609-3621 (2007).

49. Wang, $H$. et al. Regulatory features underlying pollination-dependent and -independent tomato fruit set revealed by transcript and primary metabolite profiling. Plant Cell 21, 1428-1452 (2009).

50. Ruiu, F., Picarella, M. E., Imanishi, S. \& Mazzucato, A. A transcriptomic approach to identify regulatory genes involved in fruit set of wild-type and parthenocarpic tomato genotypes. Plant Mol. Biol. 89, 263-278 (2015).

51. Mazzucato, A., Olimpieri, I., Siligato, F., Picarella, M. E. \& Soressi, G. P. Characterization of genes controlling stamen identity and development in a parthenocarpic tomato mutant indicates a role for the DEFICIENS ortholog in the control of fruit set. Physiol. Plant 132, 526-537 (2008).

52. Theißen, $G$. Development of floral organ identity: stories from the MADS house. Curr. Opin. Biol. 4, 75-85 (2001).

53. $L i, X$. M. et al. Functional conservation and divergence of four ginger AP1/AGL 9 MADS-box genes revealed by analysis of their expression and protein-protein interaction, and ectopic expression of AhFUL gene in Arabidopsis. PLOS ONE 9 e114134 (2014). 